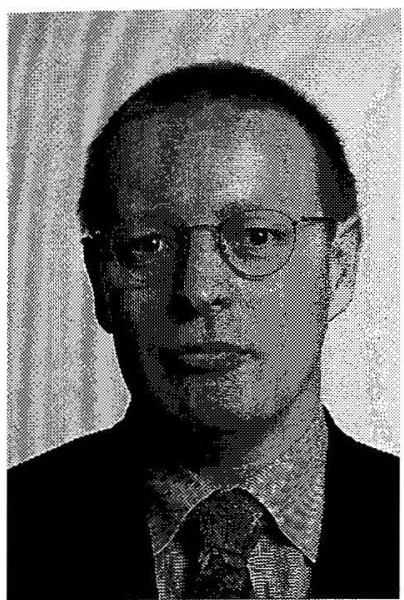

\title{
A REPORT CARD ON THE \\ NEW ZEALAND LABOUR \\ MARKET: IMPROVING, COULD DO BETTER
}

\author{
David Grimmond* \\ Labour Market Policy Group \\ Department of Labour
}

\begin{abstract}
The aim of this paper is to provide an overview of the performance of the New Zealand labour market in recent years. In particular how has the performance during the current economic cycle (defined here as since 1996) compared with that in two earlier cycles (1984 to 1989 and 1989 to 1996)? I adopt a broad definition of labour market performance, one that is consistent with the Department of Labour's overarching objective to have New Zealanders enjoying highquality working lives in thriving and inclusive communities. In taking a wide focus, this paper goes for breadth ahead of depth. I provide observations along a wide range of indicators, but often can not provide robust explanations for these observations. In these instances the main aim of the paper is to highlight areas where more in-depth research is warranted. From this broad but reasonably shallow analysis one gets a remarkably consistent theme: the performance of the New Zealand labour market has improved markedly during the 1990s but there is still scope for further improvements.
\end{abstract}

\section{Introduction}

The aim of this paper is to provide an overview of the performance of the New Zealand labour market in recent years ${ }^{1}$. In particular how has the performance during the current economic cycle (defined here as since 1996) compared with that in two earlier cycles (1984 to 1989 and 1989 to 1996)?

I adopt a broad definition of labour market performance, one that is consistent with the Department of Labour's overarching objective to have New Zealanders enjoying high-quality working lives in thriving and inclusive communities. In order to achieve this overarching outcome, the Department is focussed on a number of second tier (intermediate) target outcomes:

- Creating greater opportunity for all in New Zealand

- Improving labour market participation

- Developing a skilled and knowledgeable workforce that is able to meet future needs
- Facilitating thriving well-settled and inclusive communities

- Encouraging fair and productive employment relationships

- Minimising the social and economic costs of injury

- Minimising adverse environmental impacts of work and workplaces

- Enhancing trust in the institutions of government through access to independent review and decision making

This list implies a wide range of possible ways of assessing labour market performance. In taking a wide focus, this paper goes for breadth ahead of depth. I provide observations along a wide range of indicators, but often can not provide robust explanations for these observations. In these instances the main aim of the paper is to suggest that these are areas where more indepth research is warranted.

\footnotetext{
* The views represented in this paper are the author's own and should not be taken to represent the views of the Department of Labour.
} 
From this broad but reasonably shallow analysis one gets a remarkably consistent theme:

The performance of the New Zealand labour market has improved markedly during the 1990s but there is still scope for further improvements.

Other themes include:

One needs to look at information about the labour market from many angles to build understanding of labour market performance.

Along a number of different dimensions, there appears to be a fundamental difference in the operation of the labour market pre- and post- the early $1990 \mathrm{~s}$. However, there have also been strong differences in economic performance on either side of this divide as well. Gaining a better understanding of the interaction between economic and labour market performance would be a fruitful area for future research.

Economic performance bolsters indicators of recent labour market performance. That is, a downturn in the economy will see some reversal in many areas of labour market gains in recent years.

The employment opportunities have improved for those with qualifications and the workforce appears to have steadily up-skilled during the 1990 s.

The costs of unemployment are likely to be concentrated around those with long duration spells of unemployment. This is apparent from many perspectives, from that of: fiscal costs (eg foregone taxes and unemployment benefit costs), lost production potential, material loss to the individuals involved and through greater risk of social exclusion. Thus, a key area of success has been a reduction in the duration of the median unemployment spell, from over six months in the early 1990 s to around three months in 2001. However, the probability of people facing long unemployment spells remains high relative to those prevailing in the mid-1980s.

There remain groups that are overexposed to unemployment and the risk of unemployment. The risks of facing spells of unemployment in an economic downturn are considerably higher for non-European ethnic groups, the young and the lower qualified.

Some simple exploratory analysis indicates that wages in New Zealand are not as responsive to economic forces as might be desirable from either labour market or economic performance perspectives. This appears to have boosted levels of unemployment, especially in economic downturns and has potentially slowed adjustments to exchange rate shocks (and paradoxically probably exacerbated the need for later inter-industry shifts in employment).

\section{Defining labour market performance}

Labour market performance is about how well workers capabilities are matched with appropriate (paid) jobs or (unpaid) activities. How well does the combination of market forces, government regulations and legislation (eg employment relations legislation like the Employment Relations Act 2000), and government policies (eg active labour market policies, education policies, the benefit system etc) combine to match individuals with jobs that maximise their (present value) of labour income?

Labour market performance is strongly inter-linked with, but not the same as, economic performance. Labour market performance is a subset of economic performance, which also encapsulates the performance of product markets and capital markets. While a strongly performing labour market may be regarded by many as a prerequisite for strong economic performance, it is not a guarantee of economic success. A country or region can have a stagnating economy despite the presence of strong indicators of labour market performance, eg Southland had the lowest unemployment rate of New Zealand regions in 2001, yet this followed six years of population and employment contraction. Likewise countries can enjoy comparatively high levels of wealth despite having large groups of their society continually unemployed, eg France.

Figure 1: Employment and economic growth

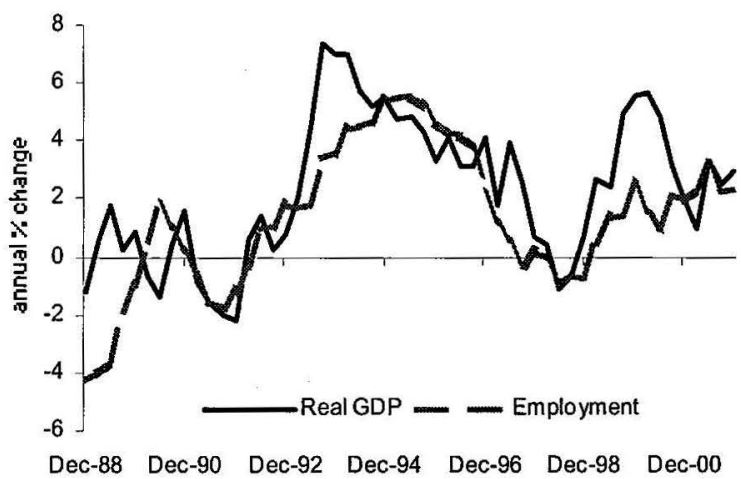

Source: Statistics New Zealand

Employment growth tends to move in a similar way to economic growth (see Figure 1). Employment growth though is usually slightly lower than economic growth, with the difference largely reflecting labour productivity growth. Employment growth during the 1991 to 1996 growth phase was very similar to economic growth, indicating a growth phase that was highly labour absorbing (ie the economic growth reflected greater use of available (labour) resources). The converse is that (labour) productivity growth was low. The more recent growth phase has experienced lower employment growth relative to economic growth, hence inferring higher labour productivity growth. 
While economic performance can have a strong influence on employment growth (and vice versa), the key difference between the two concepts is the wage dimension. A country or region with a better labour market performance will have less days lost due to unemployment and greater levels of labour utilisation (ie higher employment rates). But a country or region with a better economic performance will have higher average incomes and wages (from a purchasing power perspective) $)^{2}$.

There will be interaction (synergies as well as trade-offs) in the labour, social and economic performance of a society. A well performing and inclusive labour market is likely to foster both economic performance and social cohesion. Conversely economic and social cohesion problems are likely to have repercussions for labour market performance.

\section{Economic activity and labour market performance}

Figure 2 presents a depiction of New Zealand's Okun curve over the 1986-2001 period (named after the American economist Arthur Okun). An Okun curve depicts the short run (negative) relationship between unemployment and aggregate demand (proxied here by the HLFS unemployment rate and NZIER's QSBO based capacity utilisation measure). A shift along the horizontal axis represents a change in aggregate demand (the further to the right the higher the level of economic activity). The vertical axis proxies the labour market ramifications of changes in aggregate demand.

\section{Figure 2: New Zealand Okun curve, 1986 - 2001}

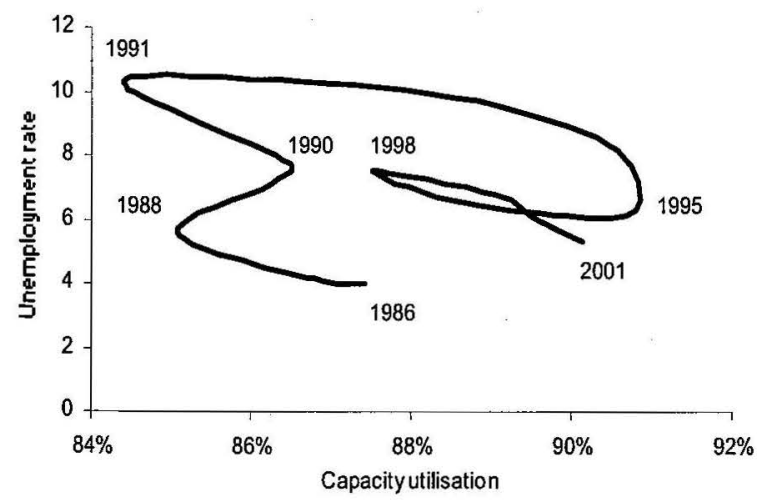

Source: NZIER, HLFS, LMPG

Okun curves provide an illustrative summary of overall labour market performance. Persistently high levels of unemployment can indicate the presence of disequilibrium in the labour market. The presence of unemployment implies that the supply of willing labour exceeds the demand of prospective employers. Persistent unemployment implies:
- a continual large flow of people in and out of unemployment,

- an inability for the labour market to match available workers with suitable jobs (ie an inability for all prospective employers and employees to agree on a wage rate that is agreeable to both parties) or

- a combination of the two.

In practice all economies experience imperfections in their labour markets and unemployment rates in excess of that explained by short-term unemployment spells. In addition unemployment tends to rise when aggregate demand falls (ie wages do not fall to adequately reflect the falling demand for labour). This correlation of decreases in demand and increases in unemployment is reflected by a leftward and upward movement in the Okun curve (as per 1986 to 1988, 1990 to 1991 and 1995 to 1998 in Figure 2.1).

That unemployment rises during an economic downturn is not generally regarded as being symptomatic of a poorly performing labour market ${ }^{3}$. Instead it is the speed with which unemployment falls with an increase in demand that highlights the ability of a country's labour market to match prospective workers with jobs. If the decline in unemployment rates during an economic upturn mimics the rise in unemployment during the economic downturn it is an indication that the matching process in the labour market is performing well (at least in aggregate).

Conversely, if there are considerable delays between a recovery in economic activity and falls in unemployment, it suggests that the matching process in the labour market may not be operating as well as possible. It also suggests that the costs of economic declines are being borne disproportionately by a concentrated group of society (ie the unemployed). Further analysis of who is unemployed and for how long is of course required before one can be too categorical, but evidence of 'high' or rising levels of unemployment coinciding with 'high' or rising levels of aggregate demand are at first blush indicators of a labour market that is not operating as well as it could perhaps be.

Looking at New Zealand's experience over the last three economic growth phases, there are signs of improvements in the job matching performance of the labour market. During the muted 1989 growth phase, the increases in the unemployment rate continued unabated. The longer more sustained 1991 to 1996 growth phase was accompanied by falls in unemployment, however the declines were at first quite modest compared both with the levels of demand prevailing and with the previous increases in unemployment during the late 1980 s.

Since the mid-1990s there are signs that there has been a marked improvement in the labour market's job matching capabilities. The decline in unemployment accelerated in 1995. Then while unemployment rose slightly with the 
1997-1998 fall in demand, this has been matched with comparable declines in unemployment in the 1999 to present growth phase.

Figure 3: Changes in Okun curve trends

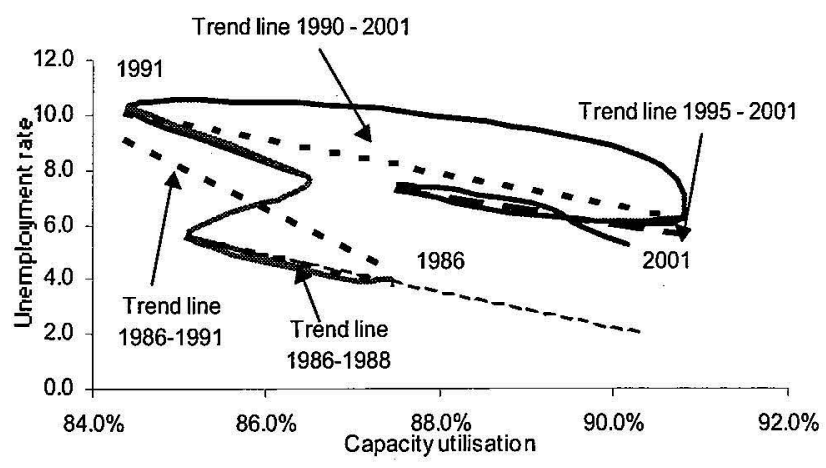

Source: $L M P G, S N Z, N Z I E R$

There is insufficient data to be too categorical about this modest circumstantial evidence of improvements in the performance of the labour market. For a start, since 1993, the levels of aggregate demand have consistently been above those experienced in the 1980s. Thus one might expect some improvement in unemployment rates, and the super critical could argue that with a "1980s economy" and current levels of aggregate demand one might expect unemployment rates considerably below those currently prevailing. That is extending the apparent trend relation between capacity utilisation and unemployment prevailing in the 1986 to 1988 would suggest that at current levels of capacity utilisation, an unemployment rate of $2 \%$ might have been achieved in 2001 instead of the $5.3 \%$ actually achieved (see Figure $3)$.

Some counters to this perspective include:

- While still above rates prevailing in the mid1980 s, the $5.3 \%$ unemployment rate achieved in 2001 was lower than the $6.7 \%$ rate suggested by the 1990 - 2001 trend, and even the $6.1 \%$ suggested by the $1995-2001$ trend.

- Experiences in a number of countries illustrate that declines in unemployment are not guaranteed to accompany improvements in levels of economic activity, even after many years of growth.

- The causal link between demand and unemployment is not necessarily one way, for example problems in the performance of the labour market in the 1980 s were perhaps contributory factors to the low levels of demand prevailing then. Likewise an improving labour market performance could be contributing to the sustained high levels of economic activity in recent years.

\section{International comparisons}

In this section I compare some indicators of New Zealand's labour market performance with that of four other OECD countries, Australia, France, the Netherlands and the United States. The choice of countries to compare with has been deliberate: Australia is our closest neighbour and shares many similarities with New Zealand; France is a 'typical' European economy that has experienced some chronic labour market problems over an extended number of years; the Netherlands provides an alternative European example of rapidly improving labour market outcomes; and the United States provides an example of a high employment labour market.

Employment growth has tended to be faster than population growth during the 1990s. Working age population growth during the 1990s was relatively slow in the two European countries averaging around $1 / 2 \%$ per year compared with $1 \%$ for the United States and 1.4\% for both New Zealand and Australia. Except for France employment growth has tended to outstrip population growth, with the growth in Dutch employment the most spectacular $(2.1 \% \mathrm{pa})$.

There appear to be three camps of unemployment outcomes in the 1990s (see Figure 4):

- the Netherlands and the United States who began the 1990 s with reasonably low unemployment rates had further steady declines to $3.5 \%$ (for the Netherlands in 1999) and $4.0 \%$ (for the United States in 2000),

- initial increases followed by strong declines in Australia and New Zealand reaching $6.2 \%$ and $6.0 \%$ respectively in 2000 , and

- France whose unemployment rate continued to increase to a peak of $12.5 \%$ in 1997 , but which had declined to $9.7 \%$ in 2000 .

Figure 4: International comparison of unemployment rates

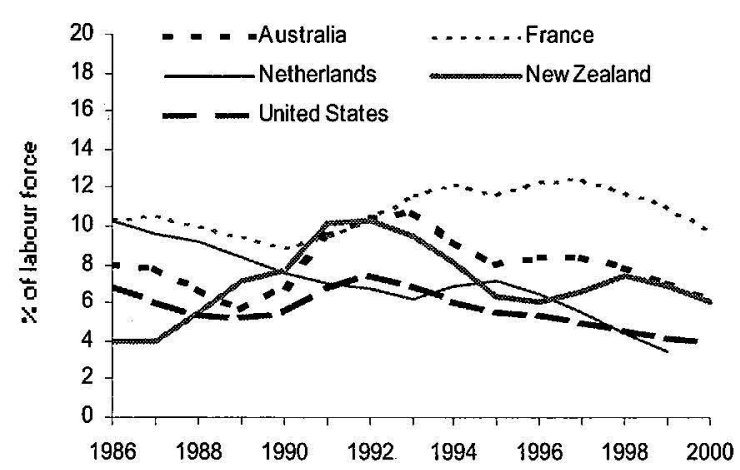

Source: $O E C D$ 
The performance of the Dutch labour market during the 1990s looks less spectacular when one takes into account the typical time spent in unemployment by the unemployed. Although unemployment numbers have fallen in recent years, unemployment tends to be for a long time for the Dutch. The median unemployment spell has persistently remained at around one year (see Figure 5).

Figure 5: Median duration of unemployment spells

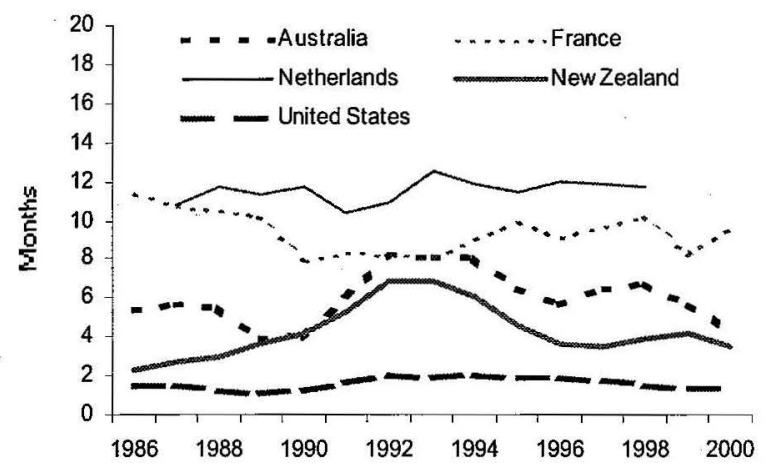

Source: $O E C D$, calculated by $L M P G$

While the median unemployment spell for New Zealanders increased to over six months in the early 1990 s, this increase was largely reversed in the late 1990s. In 2000, the median unemployment spell in New Zealand was $3 \frac{1}{2}$ months. This is still considerably more than the 1.3 months calculated for the United States, and even the 2.3 months calculated for New Zealand in 1986, but it is a significant improvement on ten years earlier and considerably superior to European experiences.

\section{Disparities in labour market outcomes}

This section examines the different labour market experiences of different groups within New Zealand. The data analysed is largely disaggregations of data series from the Household Labour Force Survey (HLFS). Different labour market experiences are examined based on:

- Gender

- Ethnicity

- Age

- Qualifications

\section{Gender}

There has been very little difference in unemployment rates reported for men and women, with female unemployment rates being just slightly lower than that reported for men.
Figure 6: Unemployment rate by gender

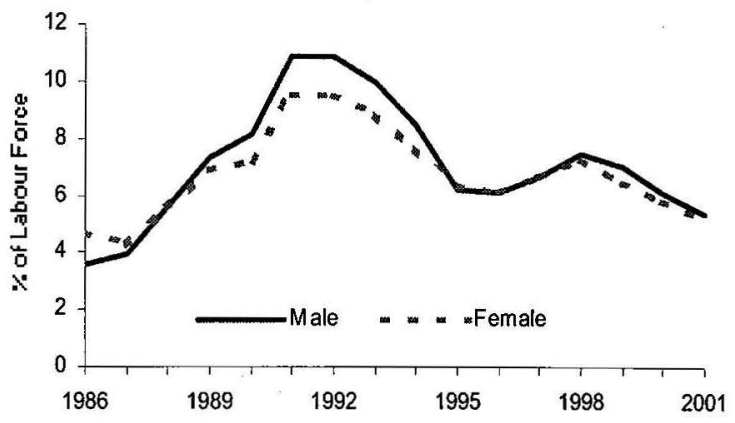

Source: Statistics New Zealand (HLFS)

Participation rates are significantly higher for men, but the gap has narrowed considerably over the past 15 plus years. Male participation has reduced from $79 \%$ to $74 \%$ (but note this all occurred between 1987 and 1990, male participation rates have remained very stable since 1990). Female participation rates have increased from $54 \%$ to $58 \%$, implying a reduction in the participation rate gender gap from 24 percentage points in 1987 to 16 percentage points in 2000 .

\section{Figure 7: Participation rates by gender}

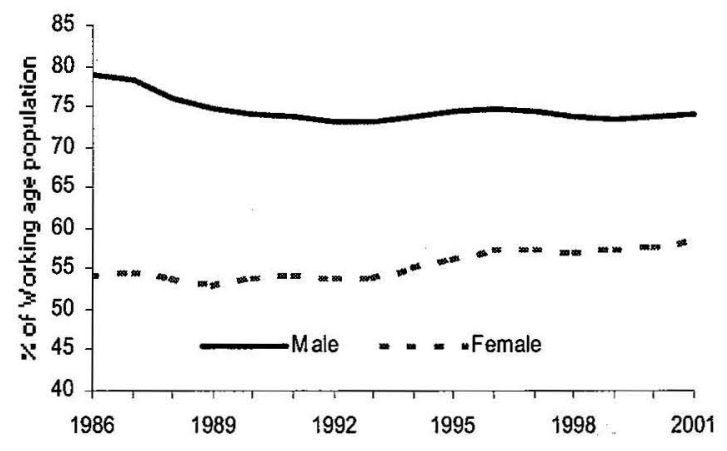

Source: Statistics New Zealand (HLFS)

\section{Ethnicity}

Pakeha unemployment rates have been far more stable over the review period than experienced by other ethnic groups. In particular Pacific and Maori unemployment rates approached $30 \%$ in the early 1990 s. While there have been substantial reductions in Maori and Pacific unemployment rates since, and are now approaching their 1980 s levels, they remain considerably above rates prevailing for Pakeha. Indeed Maori unemployment rates have never been below $10 \%$ at any point in the review period. 
Figure 8: Unemployment rate by ethnicity

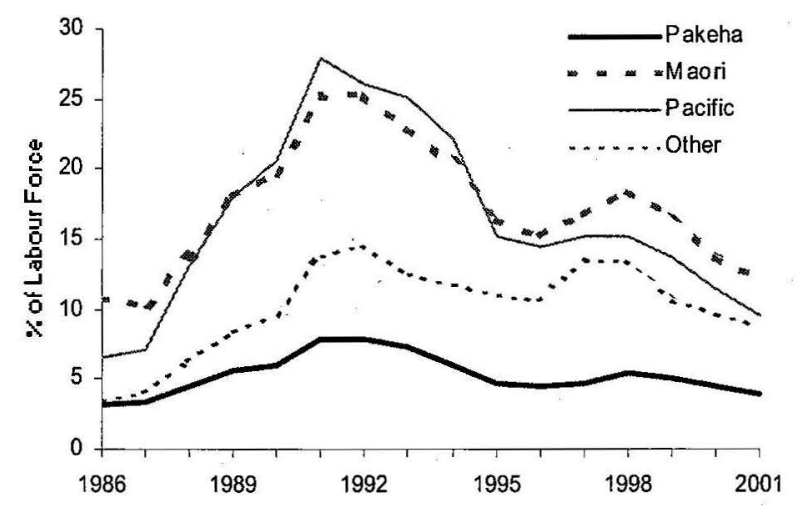

Source: Statistics New Zealand (HLFS)

European unemployment rates in 2001 were below 4\%, very close to their 1986 review period low. This suggests that the 'structural' increase in the unemployment rate since the 1980 s has been in general a non-European phenomenon. At $12.3 \%$ in 2001 the Maori unemployment rate is 2 percentage points higher than it 1987 10.3\% low. Likewise the 2001 Pacific unemployment rate was $9.6 \%, 3$ percentage points higher than its $6.5 \% 1986$ low. But the biggest wedge has come in the 'Other' ethnic group, which had a 2001 unemployment rate of $8.8 \%$, more than 5 percentage points higher than its 3.6\% 1986 low. Given that demand levels in 2001 were stronger than in 1986, there probably remain some structural unemployment hangovers in for Pakeha groups as well, they just do not seem as extensive as those experienced by the other ethnic groups.

As with unemployment, Pakeha labour force participation has remained comparatively flat during the review period. Although there was some decline in Pakeha participation in the late 1980 s, the recovery in the mid-1990s means that Pakeha participation rates in 2001 , at $68 \%$ of the working age population, were higher than their 1980s levels.

Figure 9: Participation rates by ethnicity

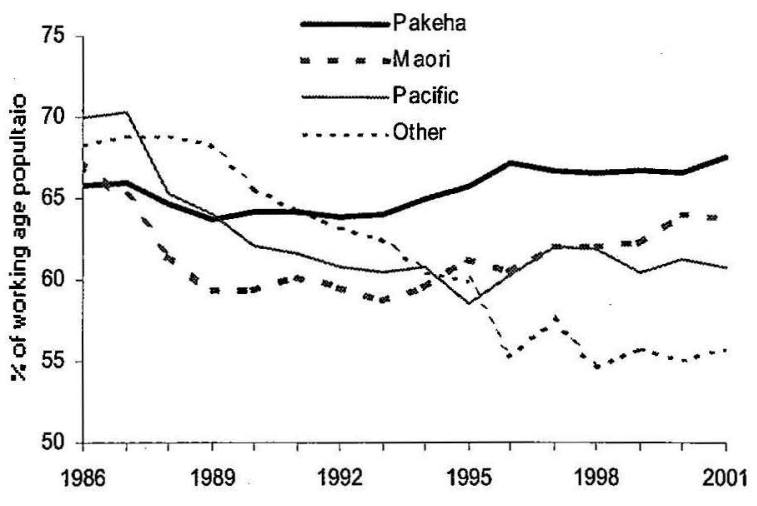

Source: Statistics New Zealand (HLFS)

Participation rates for other ethnic groups still remain considerably below their 1980 s levels. Indeed there has been an almost complete reversal from the pre-1990 period, with Pakeha moving from the lowest participating group to being now well above that of other ethnic groups. The change has come about more from reductions in non-Pakeha participation than from the modest increase in Pakeha participation. Maori and Pacific particpation has followed a similar pattern of large falls in participationin the late 1980s, followed by stability at these lower rates in the 1990s. There have been signs of some recovery in Maori participation since the mid 1990s, but it is less clear for Pacific people.

The decline in participation for the 'Other' ethnic group was a 1990s phenomenon, that has had a different source from that of the decline for Maori and Pacific people. Further research is required to explore the reasons behind this drop in participation for the Other ethnic group in the $1990 \mathrm{~s}$, but it is likely that this is related to the rapid growth in immigration. For example, a significant proportion of new migrants would be categorised in the Other ethnic group within the HLFS. Candidate reasons for this observed reductionin participation include: a more traditional family structure in which women don't seek work outside of house, difficulties in finding appropriate employment opportunities, and/or the larger numbers of foreign students studying in New Zealand experienced during the 1990s.

One has to balance this evidence of low participation with the very impressive employment growth recorded for the Other ethnic group during the current business cycle, growing by 51,600 (or $71.3 \%$ ) in the 5 years to March 2002. This type of evidence reinforces views that immigration has strongly influenced recent labour market statistics for the Other ethnic group.

Employment data indicates some success in upskilling for Maori and Pacific people. For example, of the 36,100 net increase in Maori employment over half $(18,600)$ of the new jobs were in professional and associate occupations. But while the pace of employment growth in professional type occupations is impressive, employment for Maori and Pacific people remains concentrated in lower skilled occupations. Around three-quarters of Maori and pacific employment in the March quarter 2002 was classified as clerical or production type work. Labour market experiences of lower qualified workers tend to be more volatile and sensitive to the overall performance of the economy. The inference is that, despite the positive indications of upskilling for Maori and Pacific people, the rise in unemployment that will accompany the next economic downturn will once again impact more severely on Maori and Pacific groups.

Age

Unemployment rates tend to decline with age. The volatility of unemployment rates (ie their sensitivity to the business cycle and demand conditions) also appear to decline with age. 
Figure 10: Unemployment rate by age

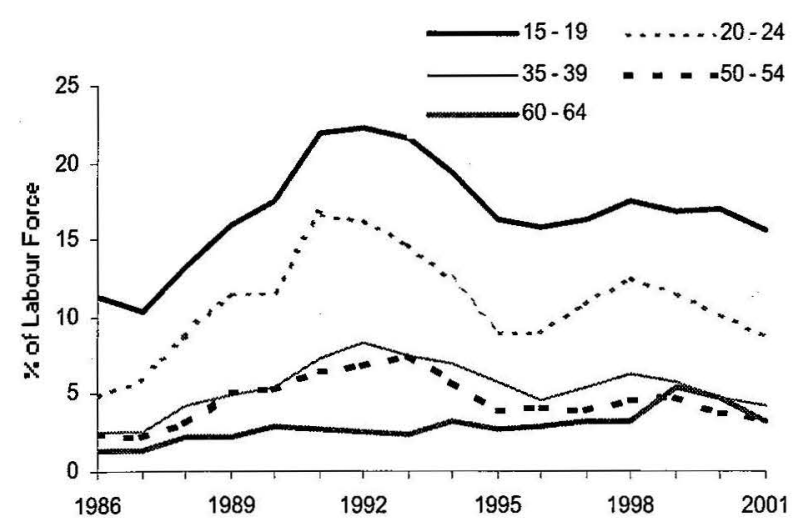

Source: Statistics New Zealand (HLFS)

The one exception to these 'rules' seems to be the 60-64 age group, which has experienced a steady increase in unemployment rates and now appears to be very similar to other prime age unemployment rates. This development seems to be consistent with the increase in participation that has accompanied the shift to delaying eligibility to superannuation from 60 to 65 years of age that gradually took place during the 1990 s. The 2000 and 2001 decline in unemployment for this group indicates that having increased to unemployment rates shared by other prime aged working groups, this older group also benefited from the declines in unemployment in recent years.

Participation rates presented in Figure 11 demonstrate the large increase (more than doubling) in participation experienced by the $60-64$ age group over the last decade. Participation rates for other age groups have been more stable, but some trends in this data include:

- A 10 percentage point decline in youth labour market participation from 1987 to 2001 (both for $15-19$ year olds and $20-24$ years olds). This is consistent with increases in education activity by these age groups.

- A 7 percentage point increase in the participation of the $50-54$ year old age group.

Figure 11: Participation rate by age

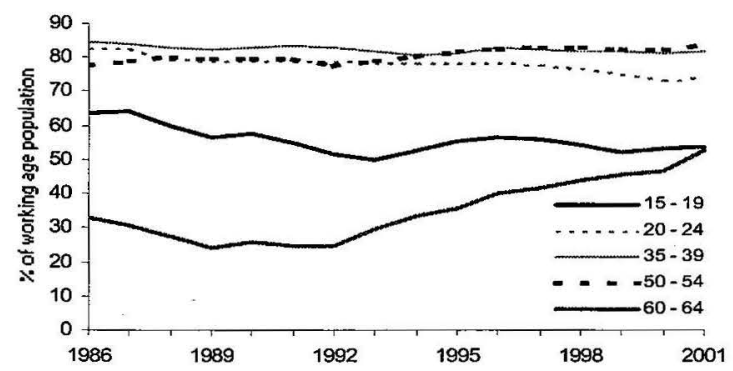

Source: Statistics New Zealand (HLFS)

\section{Qualifications}

Higher levels of qualifications appear to be associated with lower levels of unemployment. There appears to be a cyclical pattern to unemployment rates irrespective of the level of qualifications attained. The volatility of these movements seem to be higher for groups with lower levels of qualifications.

\section{Figure 12: Unemployment rates by qualifications}

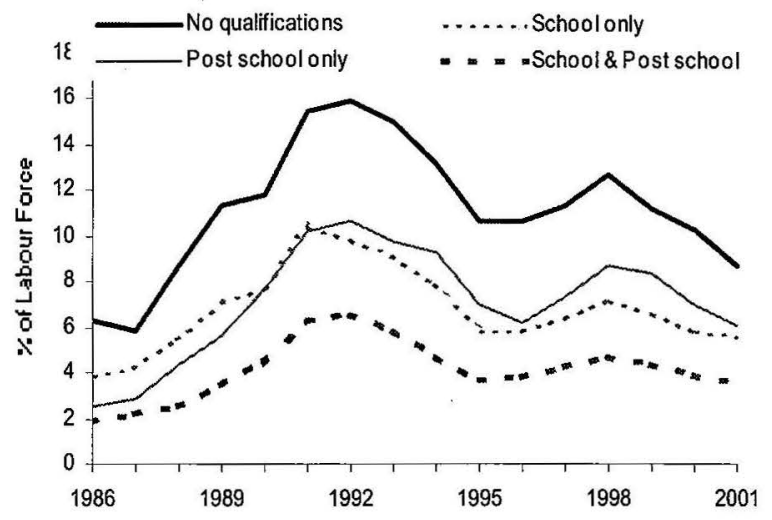

Source: Statistics New Zealand (HLFS)

There has been a considerable increase in the importance of having school and post school qualifications for employment in New Zealand (see Figure 13). The number of jobs filled by people with both school and post school qualifications almost doubled from 432 thousand jobs in 1986 to 840 thousand jobs in 2001. The importance of school qualifications as a prerequisite for employment seems also to be increasing. There has been a reasonable increase in jobs held by workers with school qualifications only from 1986 to 2001, a 109 thousand or $31 \%$ increase. Over the same period jobs held by those with no qualifications or post school only have dropped by $35 \%(185,000)$ and $16 \%(32,000)$ respectively.

Figure 13: Share of total employment by qualification

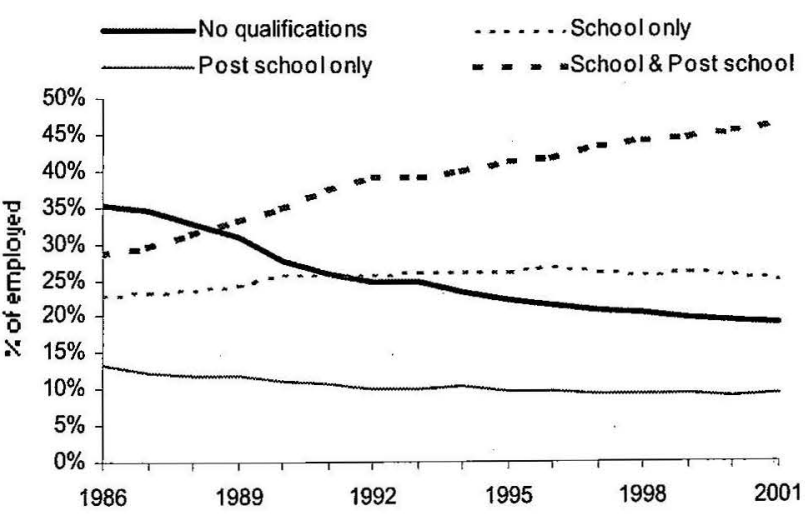

Source: Statistics New Zealand, calculated by LMPG 


\section{Wage developments}

- Wages and information about wages are critical to the functioning and performance of a labour market:

- Wage developments provide information on the returns made by workers for their work efforts. Wages are a major source of income for a large proportion of households in modern economies.

- Wages are also important signalling devices that are important in influencing the performance of the labour market. Wages represent important incentives that influence the willingness for workers to sacrifice their leisure time in order to work. Wages also represent to employers the relative cost of labour in the production process (labour costs will influence the way that employers organise their businesses and the choice of production processes).

- As Labour is not a homogeneous good (we are all different and offer potential employers a different set of skills and capabilities) differences in wage rates will influence (and be influenced by) the mix of workers available. Employers will try to employ a mix of workers that best suit their aims (eg for private sector businesses this is likely to be something associated with profit maximising). The wage that different workers receive will also influence the training/skill development choices of workers and prospective workers.

\section{Inter-industry wage effects}

There is limited evidence of increased dispersion across industries of changes in wage rates. While the New Zealand-wide average growth rate in wages has ranged from zero to $6 \%$ annual growth since 1991 , the variability in industry growth rates has been remarkably stable. The cross industry standard deviation in industry wage growth rates has typically been under $2 \%$ in every year except 2000.

But there is some evidence of persistence in wage growth differentials. While wages in New Zealand increased on average by $38 \%$ in the twelve years from 1990 to 2002 , for some industries (accommodation, personal services) the increase was barely above $20 \%$, while wages in others industries (Electricity, Finance) increased three times as much.
Figure 14: Wage growth, 1990 - 2002

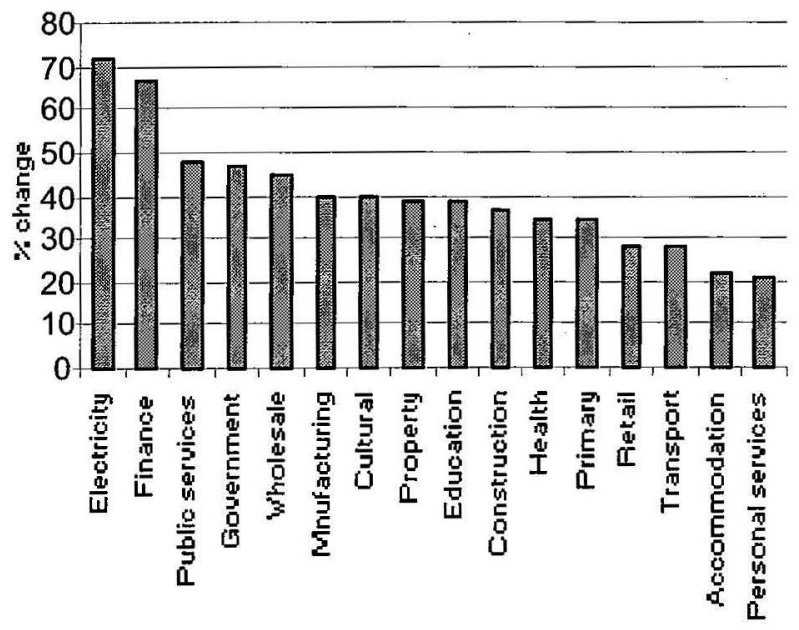

Source: Statistics New Zealand (QES), LMPG calculations

\section{Exchange rate effects on wages}

While this evidence of growing wage dispersion might raise concerns for some from a social equity perspective, from a strictly labour market performance perspective the matter most of interest is the extent that wage movements might be assisting the process of matching appropriate workers with appropriate jobs. Some initial but reasonable unsophisticated analysis would suggest that wage developments offer limited assistance to job matching processes in the New Zealand labour market.

For example, there appears to be a minimal pass through effect between exchange rate developments and the wage formation process. A $10 \%$ shift in the TWI has typically been associated with a corresponding movement in relative wages of just $0.3 \%$.

\section{Figure 15: Wage internal real exchange rate}

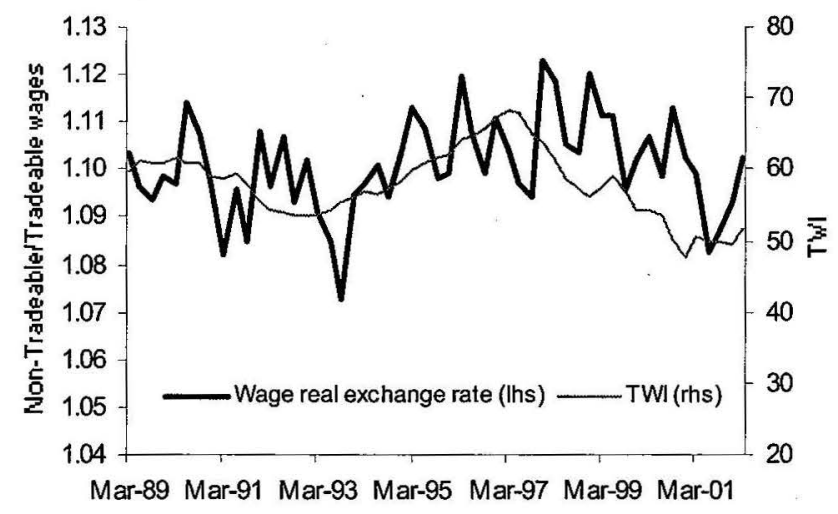

Source: Statistics New Zealand (QES, HLFS), Reserve Bank of New Zealand, LMPG calculations

It appears that around an upward trend in recent years, employment in non-tradeable industries (relative to tradeable) is sensitive to past movements in the nominal 
exchange rate, and in a far more minor way, relative wage movements mitigate some of the need for these sectoral employment changes.

Although strong caveats must be drawn around the robustness of this evidence, the implication is that wage rigidities have potentially slowed adjustments to exchange rate shocks (and by implication exacerbated the need for later inter-industry shifts in employment).

\section{Do wages paid to workers reflect their value to employers?}

Text book theory implies that the wages paid by employers should reflect the revenue earning capacity that the work done by employees yields for their employers. Generalising this to the real world means that actual wages and warranted wages should tend to grow at similar rates over time, and that any sustained divergences in these growth rates are likely to reflect changes in economic power between employers and employees (ie changes in the share of the economic rent between capital and labour).

A way of examining the match between the cost of labour with the revenue generation of employed labour is to compare movements in real income wages (wages deflated by the CPI) with movements in warranted wages. We define movements in warranted wages as coming from changes in labour productivity and the relative price of producers output prices (ie a concept of terms of trade movements) ${ }^{4}$. Specifically based on an arbitrary base period of the March quarter $1989^{5}$, the warranted wage adjusts due to increases in the GDP to employment ratio and changes in the PPI (output) to CPI ratio. These are presented in Figure 16.

\section{Figure 16: Real and warranted wages}

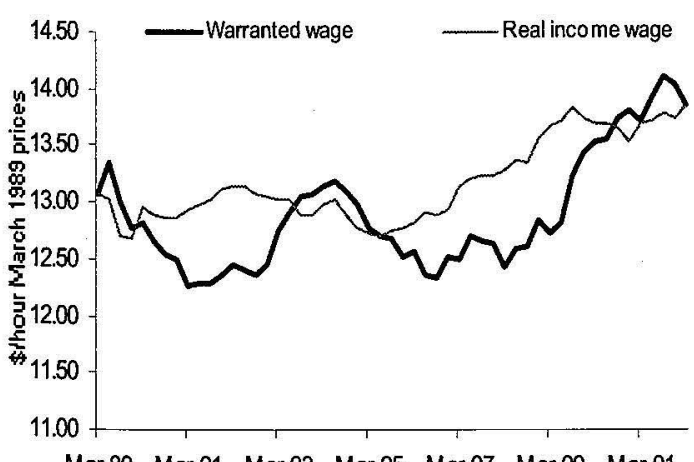

Source: Statistics New Zealand (QES, HLFS, GDP, CPI, PPI), LMPG calculations

Given that the base period chosen (March quarter 1989) is relatively arbitrary, one can not place too much inference on the measure of the gap between the warranted and real income wage. A different choice of base period would alter the size of the wage gap at every point and even the sign on the gap at many cases.
However, by coincidence, the warranted and real income wage are virtually equal at both ends of the time periods graphed in Figure 16. This implies that over this thirteen year period the warranted and real income wage did in fact increase by the same amount. But even a cursory glance at Figure 16 indicates that it would be hard to conclude, other than a similar trend growth rate, that the two time series were very similar in any other respect.

Figure 17 compares the wage gap (ie the real warranted wage less the real income wage as depicted in Figure 16) with the national unemployment rate. While our confidence in the absolute size of the wage gap is low (ie we can not be certain that the zero line ( $\mathrm{x}$-axis) is in the right place) there is some validity in the comparison with the unemployment rate in Figure 17, as theoretically one would expect to see a negative relationship between the unemployment rate and measures of the wage gap.

A decrease in the wage gap implies a decrease in the profitability emanating from hiring labour (employers are spending more on labour for the same level of revenue or receiving less revenue for the same labour costs). Thus a decline in the wage gap, for whatever reason, is likely to be symptomatic with increases in unemployment. Conversely one might expect declines in unemployment when the wage gap is increasing. Although the symmetry is not perfect ${ }^{6}$, the time series presented in Figure 17 generally support these theoretical contentions.

\section{Figure 17: Wage gap and unemployment rate (warranted wage less real income wage)}

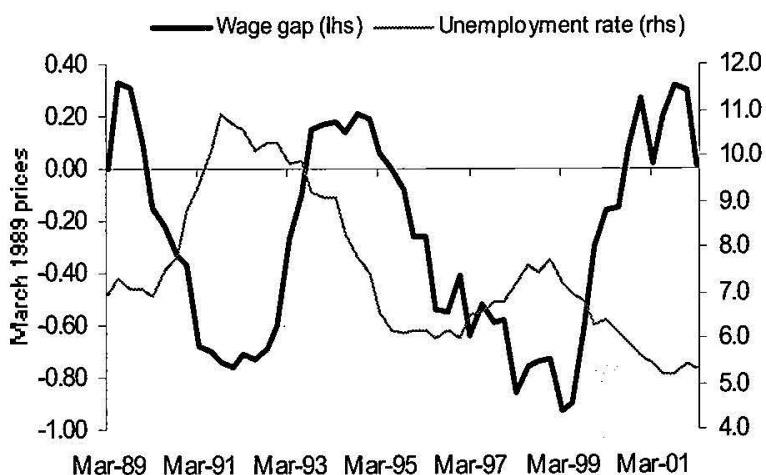

Source: Statistics New Zealand (QES, HLFS, GDP, CPI, PPI), LMPG calculations

Exploratory (and ad hoc) regression analysis suggests a strong correlation between this wage gap measure and the New Zealand unemployment rate. Although one can not put any reliance on this, it does suggest that more sophisticated research is warranted. For this exploratory analysis would imply that distortions to the wage setting process could be having a sizeable impact on labour market performance (increasing peak unemployment rates by more than one percentage point perhaps) and thus imposing considerable disruption to the lives of many New Zealanders. 


\section{Work life balance}

Since 1986 both the number of workers and the aggregate number of hours worked by workers have increased by around $18 \%$. The implication is that the average number of hours worked per worker has remained roughly unchanged. Calculations of median hours worked indicate that while there has been a modest fall in the typical weekly hours worked by female workers (from around 35 hours to around 34), the median hours worked by male workers have remained remarkably steady at just under 41 hours per week.

Such aggregate figures however mask some interesting sub-aggregate trends in individuals work intensities. In particular there are signs that those who already work long hours (ie over 40 hours per week) are typically working longer hours now than in the 1980s. The median male worker working over 40 hours per week worked around 51 hours per week in 1986, by 2001 this figure had increased to 52 hours. For long-working female workers there was a two hour increase in the typical working week from $48 \frac{1}{2}$ to $50^{1 / 2}$ hours.

If we split workers by gender and by HLFS records of hours worked each week into three groups (those working less than, equal to or over 40 hours per week), we observe the following descriptive information about work habits during the last 15 years (see Figure 18):

- The majority (just under two-thirds) of women who work tend to work less than 40 hours per week.

- For men the largest proportion (just under one half) work over 40 hours.

- Over the fifteen year period there have been downward trends (for both sexes) in the proportion of workers working 40 hours and under and an upward trend in the proportions working over 40 hours per week.

Figure 18: Trends in hours worked, 1986 - 2001
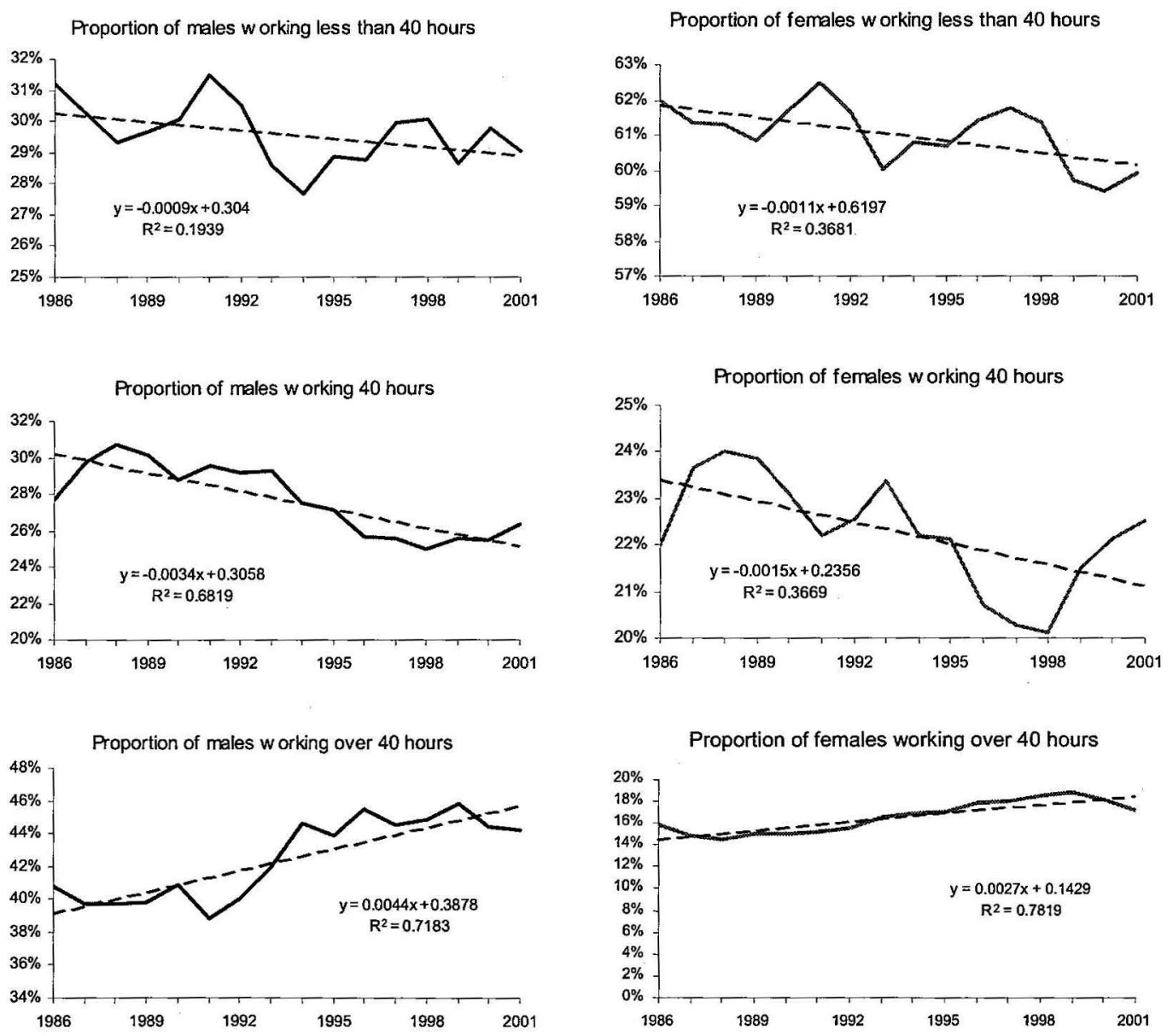

Source: Calculated from SNZ HLFS data by LMPG 
Table 1: Contribution to growth in hours worked in the economy by workers working different weekly hours

1986 - $2001 \quad$ By aggregate hours worked By number of workers

\begin{tabular}{lcc}
\hline Working less than 40 hours & $-1.0 \%$ & $0.4 \%$ \\
Male & $2.7 \%$ & $6.5 \%$ \\
Female & $1.7 \%$ & $6.9 \%$ \\
Total & & \\
Working 40 hours & $0.9 \%$ & $0.8 \%$ \\
Male & $3.5 \%$ & $3.0 \%$ \\
Female & $4.4 \%$ & $3.7 \%$ \\
Total & & \\
Working more than 40 hours & $7.6 \%$ & $4.6 \%$ \\
Male & $4.2 \%$ & $2.7 \%$ \\
Female & $11.8 \%$ & $7.3 \%$ \\
Total & & \\
All Hours worked & 1 & $5.9 \%$ \\
Male & $7.5 \%$ & $12.2 \%$ \\
Female & $10.3 \%$ & $18.1 \%$ \\
Total & $17.9 \%$ & \\
\hline
\end{tabular}

1. For a small proportion of respondents to the HLFS there is no record of hours worked. This means that the sum of contributions by different hours worked do not necessarily sum to the totals presented in the all hours block.

Source: Calculated from SNZ HLFS data by LMPG

- While there is a very similar downward trend for both male and female workers working less than 40 hours a week (the proportion has tended to decline by 0.1 percentage points each year), the proportion of male workers working 40 hours per week has been declining twice as fast as for females.

- These declines in number working shorter weeks is being replaced by workers working in excess of 40 hours per week. The upward trend for women is about two-thirds that for men.

Table 1 indicates that while just $40 \%$ of the employment growth experienced in the last 15 years came from people who tend to work over 40 hours a week (a 7.3\% contribution to the $18.1 \%$ employment growth), this group of workers contributed $66 \%$ of the increase in hours worked in the economy over this fifteen year period (a $11.8 \%$ contribution to the $17.9 \%$ increase in hours worked).

This evidence of an increasing reliance of the economy on about one-third of the work force raises a number of ancillary questions related to one key one: is this development in working patterns economically efficient or does it represent some form of market failure? For example, are people being "forced" to work longer hours?

Are workers working longer hours to compensate for a lack of wage rises?

Figure 19: Pooled time series trend analysis: wages and hours worked

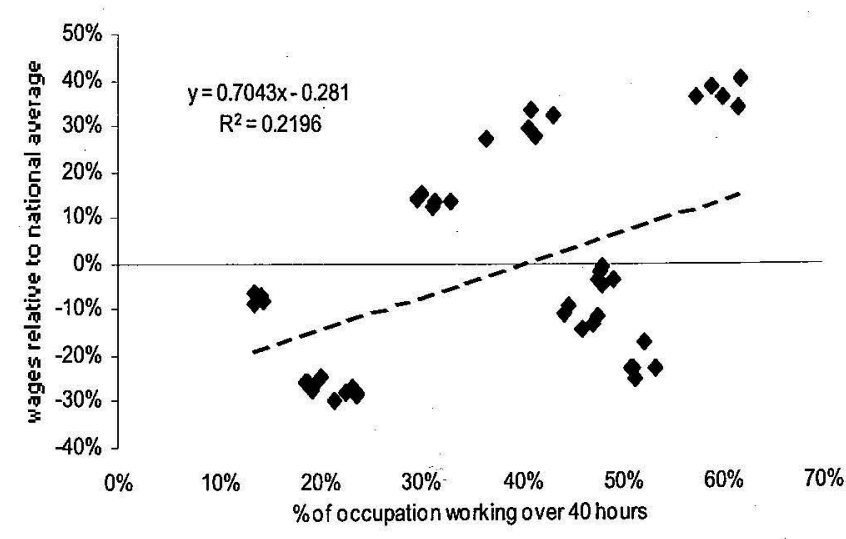

Source: LMPG calculations based on data from SNZ, Labour Market Statistics (1997 to 2001)

Answering such questions requires more in depth analysis than can be provided here, but we present below some initial analysis that indicates (or at least is 
consistent with the perspectives) that the increases in hours worked have been largely voluntary and have not been a response to a lack of wage growth.

Figure 19 indicates that there is a positive correlation between the occupational incidence of people working over 40 hours per week and the occupational average wage relative to national average wages. Occupations that tend to be paid above average tend to have a higher proportion working longer hours. This relationship increases when farmers are excluded from the analysis. This suggests that those who work long hours tend to be either well rewarded or receive some other lifestyle (or non-wage) return from the long working profession they choose to work in. The other observation one might make is that between occupation variations appear to be stronger than any over time adjustments.

\section{Concluding comments}

This paper has concentrated on making observations about recent labour market performance. It is beyond the scope of this paper to offer much in the way of explaining the reasons behind such observations. However, our observations do highlight a number of priority areas where further analysis would boost our understanding of what factors are key to influencing the performance of

\section{Notes}

1 This paper extracts from a more comprehensive forthcoming paper.

2 Adding other dimensions to this, such as social performance requires analysis of the distribution of outcomes and opportunities, in addition to aggregate or average measures. A complete analysis of national performance requires the assessment of other factors such as environmental impacts, citizen safety, levels of fairness (including discrimination) and so on.

3 Although ideally one might hope that unemployment increases in an economic downturn might be mitigated by declines in wage and/or hours worked rather than lost jobs, economic downturns are times when poor performing firms tend to be weeded out, so some rise in unemployment is highly likely. Thus from a labour market performance criteria, while one would hope that the extent of an increase in unemployment during a downturn is minimal, it is perhaps more important that the period of increased unemployment and the length of time each individual spends in unemployment are as short as possible.

4 Thus:

real income wages (quarter $\mathrm{t})=\mathrm{w}_{\mathrm{t}} / \mathrm{CPI}_{\mathrm{t}}$ the New Zealand labour market. In particular we would recommend further analysis is warranted in the following areas:

- Examining the relationship between economic activity and labour market performance.

- Clarifying the extent that there have been structural changes in the operations of the New Zealand labour market and identifying the causal factors behind any such changes.

- Micro data analysis of factors influencing working arrangements, eg hours per week worked, part-time versus full-time work, one versus multiple jobs (or perhaps a portfolio of jobs).

- The influence of wage signals in influencing the allocation of labour in the labour market (eg supply and demand signals), the relative importance of the performance of the labour market to labour market outcomes relative to the influences of capital market and product market signals, and the impact of labour market regulations on labour market outcomes.

warranted wage (quarter $\mathrm{t}$ ) $=$ real income wage $\mathrm{t}_{\mathrm{t}=0}+$ $\Delta \mathrm{WW}_{\mathrm{t}}$

where $\Delta \mathrm{WW}_{\mathrm{t}}=\left(\mathrm{GDP}_{\mathrm{t}} / \mathrm{emp}_{\mathrm{t}}\right) /\left(\mathrm{GDP}_{\mathrm{t}=0} /\right.$ employment $\left._{\mathrm{t}=0}\right)$

$$
+\left(\mathrm{PPI}_{\mathrm{t}} / \mathrm{CPI}_{\mathrm{t}}\right) /\left(\mathrm{PPI}_{\mathrm{t}=0} / \mathrm{CPI}_{\mathrm{t}=0}\right)
$$

and

w = QES average hourly earnings (all industries, all hours)

$\mathrm{CPI}=$ Consumers Price Index

PPI = Producers Price Index (all industries, outputs)

GDP = quarterly series of real gross domestic product

Emp = total employment (HLFS based)

$\mathrm{t}=0$ in the March quarter 1989

5 Chosen purely based on this being the starting point of the QES wage data available

6 In particular it appears that the responsiveness between the wage gap and the unemployment rate might be lower in recent years than it was in earlier periods. 